\title{
Severe neurological impairment in hereditary methaemoglobinaemia type 2
}

Toelle, Sandra P ; Boltshauser, Eugen ; et al

\begin{abstract}
Recessive congenital methaemoglobinaemia (RCM) due to NADH-cytochrome b5 reductase (cytb5r) deficiency is a very rare disorder. We report on two unrelated patients (4 and 2.5 years old) with RCM type 2. Developmental delay was obvious at the age of 4 months. On follow-up, both children showed severe tetraspastic cerebral palsy, profound cognitive impairment, strabismus, impressive secondary microcephaly and failure to thrive. One novel mutation in the DIA1gene was identified. Prenatal diagnosis was successfully done in both families by mutation analysis in chorionic villi or measurement of cytb5r in fetal amniotic cells. Conclusion:due to the severity of this disease and its $25 \%$ recurrence risk, prenatal diagnosis should be made available to all affected families
\end{abstract}

DOI: https://doi.org/10.1007/s00431-004-1409-x

Posted at the Zurich Open Repository and Archive, University of Zurich

ZORA URL: https://doi.org/10.5167/uzh-156439

Journal Article

Published Version

Originally published at:

Toelle, Sandra P; Boltshauser, Eugen; et al (2004). Severe neurological impairment in hereditary methaemoglobinaemia type 2. European Journal of Pediatrics, 163(4-5):207-209.

DOI: https://doi.org/10.1007/s00431-004-1409-x 


\section{Sandra P. Toelle $\cdot$ Eugen Boltshauser \\ Ekkehard Mössner · Karin Zurbriggen · Stefan Eber \\ Severe neurological impairment in hereditary methaemoglobinaemia type 2}

Received: 18 September 2003 / Accepted: 8 January 2004 / Published online: 18 February 2004

(C) Springer-Verlag 2004

\begin{abstract}
Recessive congenital methaemoglobinaemia (RCM) due to NADH-cytochrome b5 reductase (cytb5r) deficiency is a very rare disorder. We report on two unrelated patients (4 and 2.5 years old) with RCM type 2. Developmental delay was obvious at the age of 4 months. On follow-up, both children showed severe tetraspastic cerebral palsy, profound cognitive impairment, strabismus, impressive secondary microcephaly and failure to thrive. One novel mutation in the $D I$ Algene was identified. Prenatal diagnosis was successfully done in both families by mutation analysis in chorionic villi or measurement of cytb5r in fetal amniotic cells. Conclusion: Due to the severity of this disease and its $25 \%$ recurrence risk, prenatal diagnosis should be made available to all affected families.
\end{abstract}

Keywords Diaphorase $\cdot$ Hereditary methaemoglobinaemia $\cdot$ Mutation analysis .

NADH-cytochrome b5 reductase $\cdot$ Prenatal diagnosis

Abbreviations cytb5r NADH-cytochrome b5 reductase $\cdot R C M$ recessive congenital methaemoglobinaemia

\section{Introduction}

In the blood of healthy individuals, less than $1 \%$ of haemoglobin is present in the oxidised form called methaemoglobin. The major pathway for the reduction

S. P. Toelle $\cdot$ E. Boltshauser $(\bowtie)$

Division of Neurology, University Children's Hospital,

Steinwiesstrasse 75, 8032 Zurich, Switzerland

E-mail: eugen.boltshauser@kispi.unizh.ch

Tel.: + 41-1-2667330

Fax: + 41-1-2667163

E. Mössner $\cdot$ K. Zurbriggen $\cdot$ S. Eber

Division of Haematology, University Children's Hospital, Zurich, Switzerland of methaemoglobin to functional haemoglobin in human erythrocytes involves a NADH-dependent methaemoglobin reductase system. In addition to NADH, this system requires the presence of cytochrome b5 reductase (cytb5r, also named diaphorase) and cytochrome b5. Recessive congenital methaemoglobinaemia (RCM) (MIM 250800) is a very rare disorder caused by deficiency of cytb5r. Two forms of this enzyme are known, a membrane-bound form mainly found in microsomes and the endoplasmic reticulum of all tissues investigated [2,17], and a soluble form present in erythrocytes. These two forms are generated from the same gene by a combination of transcriptional and translational mechanisms $[3,10,12]$. The enzyme deficiency is usually restricted to the red cell soluble cytb5r (RCM type 1), whereas in $10 \%-15 \%$ of cases the enzyme defect is generalised to all tissues, involving both soluble and microsomal forms of the enzyme (RCM type 2). Patients with RCM type 1 have cyanosis but hardly any systemic symptoms when the methaemoglobin level is less than $25 \%$. In RCM type 2, cyanosis is associated with severe progressive neurological disability.

RCM type 1 and type 2 are caused by a defect in a single gene ( DIAl), which has nine exons and eight introns, and is located on chromosome 22 (locus DIA1; q13.31-qter) [4]. Recent literature focuses on genetic aspects and mutation analysis; here we emphasise the severe neurological outcome of RCM type 2, which is usually only vaguely described as "mental retardation" or "neurological impairment".

\section{Case reports}

Case 1

The patient, a girl, was born at term as the first child of healthy consanguineous Pakistani parents (multiple relationship). Her weight $(3820 \mathrm{~g})$, length $(53 \mathrm{~cm})$ and head circumference $(32.5 \mathrm{~cm})$ were within the normal percentile values. Cyanosis was noted within hours after birth. Methaemoglobin concentration was increased to $17 \%$ of total haemoglobin and fell to $6 \%$ after i.v. 
administration of methylene blue $(1 \mathrm{mg} / \mathrm{kg})$. Apart from the cyanosis, there were no other apparent problems, and RCM type 1 was suspected.

At the age of 4 months, when developmental delay was already obvious, the baby was referred to our hospital for further evaluation. Her head circumference was borderline microcephalic $(37.7 \mathrm{~cm})$ and her muscle tone was increased. MRI of the brain showed enlarged CSF spaces and delayed myelination. Treatment with ascorbic acid (500 mg daily) and riboflavin (40 mg daily) resulted in improvement of methaemoglobinaemia $(8 \%-12 \%)$. In the following months, the parents reported frequent vomiting and crying, and hardly any progress in psychomotor development was observed. When last seen at the age of 4 years, the girl showed marked secondary microcephaly with a head circumference of $43.4 \mathrm{~cm}$ (-5.2 SD) (Fig. 1), failure to thrive, short stature, strabismus and profound cognitive impairment. She had no command of expressive language and was not able to obey simple orders. She had severe tetraspastic cerebral palsy and was unable to sit, crawl or grasp objects. Eating was difficult because of poor coordination of chewing and swallowing. The parents have so far declined the proposed gastrostomy.

Case 2

The girl was born at term as the first child of healthy consanguineous Turkish parents (second cousins). Her weight $(2750 \mathrm{~g})$, length $(49 \mathrm{~cm})$ and head circumference $(33.5 \mathrm{~cm})$ were within the

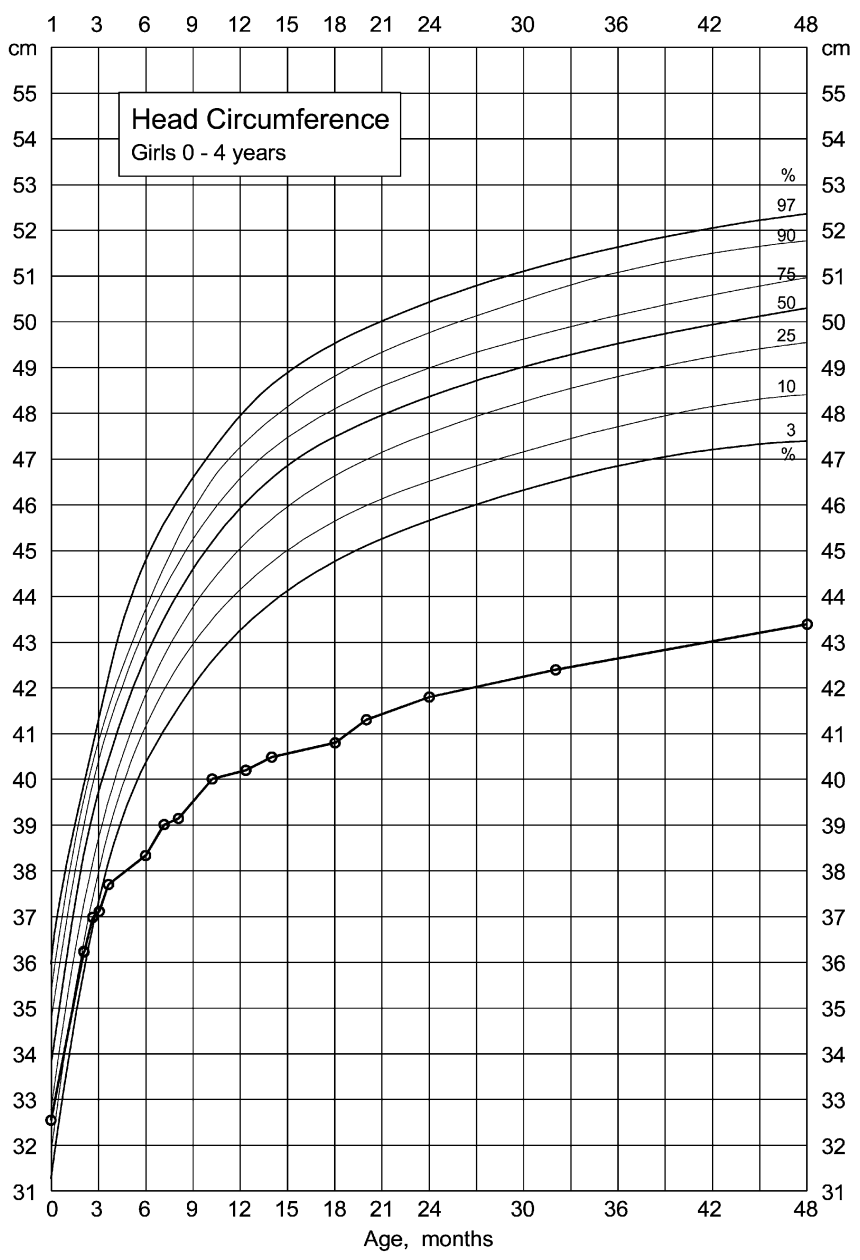

Fig. 1 Head circumference chart of case 1 illustrating early and marked secondary microcephaly normal percentile values. Cyanosis developed within hours after birth. Developmental delay was noted at 4 months. Despite the persisting cyanosis and extensive investigations, the diagnosis of RCM was not considered. At the age of 16 months, the child was referred to our hospital for diagnostic work-up of severe developmental delay.

Methaemoglobin concentration was increased to $35 \%$; therapy with ascorbic acid (1000 mg daily) and riboflavin (40 mg daily) was started and the cyanosis improved markedly. Brain MRI at the age of 5 months and 16 months showed enlarged CSF spaces, delayed myelination and a thin corpus callosum. The parents reported excessive crying and frequent vomiting resulting in failure to thrive and growth retardation. When last seen at age of 2.5 years she had severe tetraspastic cerebral palsy and was unable to sit, crawl, grasp objects or talk. There was profound cognitive impairment and strabismus. Her head circumference was $41 \mathrm{~cm}(-6.5 \mathrm{SD})$.

There was no evidence for the presence of any abnormal haemoglobin as judged by electrophoresis, nor of glucose-6-phosphate dehydrogenase deficiency. Cytb5r was not measurable in the erythrocytes of either patient. Semiquantitative tests gave no indication of reduced activity in the parents. However, a heterozygous state of $50 \%$ reduction would probably not have been detected in our assay.

Molecular analysis in case 1 has so far failed to identify the precise mutation, but absence of amplification by means of PCR of exon 2 in the patient (but not in the parents) suggested either a deletion or large insertion in this exon. Case 2 was shown to be homozygous for a hitherto unreported missense mutation in exon 8 (Arg 240 Gly). Both parents were heterozygous for this mutation. In addition, exon 9 could not be amplified in the patient (but normally in both parents).

Prenatal diagnosis was successfully done in the mother of case 1 by measurement of cytb5r in fetal amniotic cells. She gave birth to a healthy child and is currently pregnant again. The mother of case 2 had mutation analysis in chorionic villi and gave birth to a healthy girl.

\section{Discussion}

In a newborn or infant with persisting cyanosis in the absence of cardiac or pulmonary disease, the diagnosis of methaemoglobinaemia should be considered. It is important to rule out acquired forms of methaemoglobinaemia which are more common than congenital forms, glucose-6-phosphate dehydrogenase deficiency and haemoglobinopathies. Diminished methaemoglobin reduction rates and methaemoglobinaemia have been observed with haemoglobins $\mathrm{N}_{\text {Baltimore }}$, $\mathrm{I}_{\text {Toulouse }}$ and $\mathrm{M}_{\text {Milwaukee. These mutant haemoglobins presum- }}$ ably fail to interact efficiently with cytb5r [5]. The diagnosis of RCM is established by the measurement of markedly reduced cytb5r activity in the patients' erythrocytes.

As patients with RCM type 1 have only mild symptoms and a normal life expectancy, therapy is mainly "cosmetic". Oral ascorbic acid (500-1000 mg daily) and riboflavin (20-50 mg daily) can maintain the methaemoglobin concentration at acceptable levels. Unfortunately, it has no demonstrable effect on the progressive neurological dysfunction in patients with RCM type 2.

RCM type 1 and type 2 are single gene defects. Mutations that reduce stability and leave catalytic 
function intact mainly cause problems in the erythrocyte, which is dependent on enzymes synthesised in the reticulocyte persisting for the 120-day life span of the enucleate red cell [14]. Conversely, mutations that markedly reduce catalytic function cause problems in all cells expressing cytb5r and result in the type 2 phenotype [5].

The microsomal enzyme participates in the desaturation and elongation of fatty acids $[7,16]$ as well as in cholesterol biosynthesis [13]. It has been suggested that impairment of fatty acid desaturation, especially in the central nervous system, may account for the generalised systemic manifestations [9].

Both our patients presented with cyanosis within hours after birth. From the clinical viewpoint, the distinction between RCM types 1 and 2 is impossible in the newborn. The chemical results (cytb5r, methaemoglobinaemia) do not differ either. Mutation analysis is not a routine procedure and results are not available within weeks, especially in a first affected child of a family. Therefore prognosis remained open for the first weeks. Lack of normal increase in head circumference was one of the earliest signs for the distinction between RCM types 1 and 2. Developmental delay became obvious at the early age of 3-4 months. The symptoms, severe tetraspastic (dystonic) cerebral palsy, profound cognitive impairment with no command of expressive language, strabismus, failure to thrive and growth retardation, are all nonspecific. Whether the failure to thrive is the consequence of cerebral palsy or directly linked to RCM type 2 remains open. The early and impressive secondary microcephaly is due to the reduced amount of white matter. The clinical history and the symptoms are comparable to the case reports in literature, where in addition, epilepsy and a reduced life expectancy have been reported $[1,15]$.

The identification of different mutations at different positions in the DIAlgene should provide insight into the clinical and biochemical differences between RCM types 1 and 2. More than 30 different mutations have been associated with RCM types 1 and 2 [11]. RCM type 2 seems to be more often associated with nonsense mutations or deletions whereas RCM type 1 seems only to be associated with amino acid substitutions. These molecular differences might lead to variations in stability or structure of the protein or other enzymatic characteristics, resulting in the clinical differences between RCM types 1 and $2[1,8]$.

With a recurrence risk of $25 \%$, prenatal diagnosis in RCM type 2 should be offered to parents with an affected child. Reliable prenatal diagnosis can be made at an early stage in chorionic villi if a disease-associated mutation in the affected child is found. Alternatively, analysis of cytb5r activity in fetal amniotic cells is possible because of the generalised defect [6].

Acknowledgements We thank Prof. A. Pekrun, UniversitätsKinderklinik Göttingen for measuring cytb5r activity in red cells.

\section{References}

1. Aalfs CM, Salieb-Beugelaar GB, Wanders RJ, Mannens MM, Wijburg FA (2000) A case of methemoglobinemia type II due to NADH-cytochrome b5 reductase deficiency: determination of the molecular basis. Hum Mutat 16: 18-22

2. Borgese N, Pietrini G (1986) Distribution of the integral membrane protein NADH-cytochrome b5 reductase in rat liver cells, studied with a quantitative radioimmunoblotting assay. Biochem J 239: 393

3. Bulbarelli A, Valentini A, DeSilvestris M, Cappellini MD, Borgese N (1998) An erythroid-specific transcript generates the soluble form of NADH-cytochrome b5 reductase in humans. Blood 92: 310-319

4. Fisher RA, Povey S, Bobrow M, Solomon E, Boyd Y, Carritt B (1977) Assignment of the DIA-1 locus to chromosome 22. Ann Hum Genet 41: 151-155

5. Jaffé ER, Hultquist DE (2001) Cytochrome b5 reductase deficiency and enzymopenic hereditary methemoglobinemia. In: Scriver CR, Beaudet AL, Sly WS, Valle D (eds) The metabolic and molecular bases of inherited disease, 8th edn. McGrawHill, New York, pp 4555-4570

6. Kaftory A, Freundlich E, Manaster J, Shukiri A, Hegesh E (1986) Prenatal diagnosis of congenital methemoglobinemia with mental retardation. Isr J Med Sci 22: 837-840

7. Keyes SR, Cinti DL (1980) Biochemical properties of cytochrome b5-dependent microsomal fatty acid elongation and identification of products. J Biol Chem 255: 11357-11364

8. Kugler W, Pekrun A, Laspe P, Erdlenbruch B, Lakomek M (2001) Molecular basis of recessive congenital methemoglobinemia, types I and II: exon skipping and three novel missense mutations in the NADH-cytochrome b5 reductase (diaphorase) gene. Hum Mutat 17: 348

9. Leroux A, Junien C, Kaplan JC, Bamberger J (1975) Generalised deficiency of cytochrome b5 reductase in congenital methaemoglobinemia with mental retardation. Nature 258: 619-620

10. Leroux A, Mota Vieira L, Kahn A (2001) Transcriptional and translational mechanisms of cytochrome b5 reductase isoenzyme generation in humans. Biochem $\mathbf{J}$ 15: 529-535

11. Percy MJ, Gillespie MJ, Savage G, Hughes AE, McMullin MF, Lappin TR (2002) Familial idiopathic methemoglobinemia revisited: original cases reveal 2 novel mutations in NADHcytochrome b5 reductase. Blood 100: 3447-3449

12. Pietrini G, Aggujaro D, Carrera P, Malyszko J, Vitale A, Borgese N (1992) A single mRNA, transcribed from an alternative, erythroid-specific promoter, codes for two non-myristylated forms of NADH-cytochrome b5 reductase. J Cell Biol 117: 975-986

13. Reddy VV, Kupfer D, Caspi E (1977) Mechanism of C-5 double bond introduction in the biosynthesis of cholesterol by rat liver microsomes. Evidence for the participation of microsomal cytochrome b5. J Biol Chem 252: 2797-2801

14. Shirabe K, Yubisui T, Borgese N, Tang C, Hultquist DE, Takeshita M (1992) Enzymatic instability of NADH-cytochrome b5 reductase as a cause of hereditary methemoglobinemia type I (red cell type). J Biol Chem 267: 20416-20421

15. Shirabe K, Landi MT, Takeshita M, Uziel G, Fedrizzi E, Borgese N (1995) A novel point mutation in a 3-prime splice site of the NADH-cytochrome b5 reductase gene results in immunologically undetectable enzyme and impaired NADHdependent ascorbate regeneration in cultured fibroblasts of a patient with type II hereditary methemoglobinemia. Am J Hum Genet 57: 302-310

16. Strittmatter P, Spatz L, Corcoran D, Rogers MJ, Setlow B, Redine R (1974) Purification and properties of rat liver microsomal stearyl coenzyme A desaturase. Proc Natl Acad Sci USA 71: 4565-4569

17. Tamura M, Yubisui T, Takeshita M, Kawabata S, Miyata T, Iwanaga S (1987) Structural comparison of bovine erythrocyte, brain and liver NADH-cytochrome b5 reductase by HPLC mapping. J Biochem 101: 1147-1159 